\title{
An Artificial Intelligence Based Neuro-Fuzzy System with Emotional Intelligence
}

\author{
G.Sharada \\ Associate Professor, Dept. of CSE, \\ VNR Vignana Jyothi Inst. of Engg and Technology, \\ Bachupally, Hyderabad - 500090, INDIA.
}

\author{
Dr.O.B.V.Ramanaiah, \\ Professor and Head, Dept. of CSE, \\ JNTUH College of Engineering,Nachupally, \\ Karimnagar Dist - 515505. A.P, INDIA.
}

\begin{abstract}
In a very real sense we have two minds, one that thinks (rational mind) and one that feels (emotional mind). These two fundamentally different ways of knowing interact to construct our mental life. This results in two different kinds of intelligence i.e, rational and emotional. Intellect cannot work at its best without emotional intelligence. If our aim in AI is to build systems that behave like human beings then it is necessary that we incorporate elements of both rational and emotional intelligence into the system. The main concept in this paper is to develop an Intelligent Agent that exhibits the notion of emotional intelligence. The architecture that will be considered for implementation is a Neuro-Fuzzy system with concepts of artificial intelligence incorporated into the functionality of the system. The approach chosen for the implementation is Soft Computing which is basically a synergistic integration of three computing paradigms: neural networks, fuzzy logic and probabilistic reasoning, to provide a flexible framework to construct computationally intelligent systems.
\end{abstract}

The full text of the article is not available in the cache. Kindly refer the IJCA digital library at www.ijcaonline.org for the complete article. In case, you face problems while downloading the full-text, please send a mail to editor at editor@ijcaonline.org 